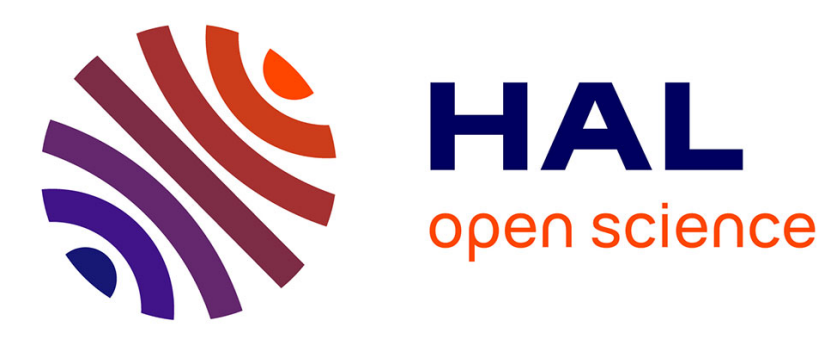

\title{
Not to throw the baby out with the bathwater. A response to Gosselain's article \\ Valentine Roux
}

\section{To cite this version:}

Valentine Roux. Not to throw the baby out with the bathwater. A response to Gosselain's article. Archaeological Dialogues, 2017, 24 (2), pp.225-229. 10.1017/S138020381700023X . hal-02958086

\section{HAL Id: hal-02958086 \\ https://hal.parisnanterre.fr/hal-02958086}

Submitted on 6 Oct 2020

HAL is a multi-disciplinary open access archive for the deposit and dissemination of scientific research documents, whether they are published or not. The documents may come from teaching and research institutions in France or abroad, or from public or private research centers.
L'archive ouverte pluridisciplinaire HAL, est destinée au dépôt et à la diffusion de documents scientifiques de niveau recherche, publiés ou non, émanant des établissements d'enseignement et de recherche français ou étrangers, des laboratoires publics ou privés. 


\title{
Not to throw the baby out with the bathwater. A response to Gosselain's article
}

\author{
Valentine Roux*
}

\begin{abstract}
In a provocative article published recently in Archaeological dialogues (23(2)), Olivier Gosselain proposes 'to get rid of ethnoarchaeology once and for all, and join forces with other, more serious, disciplines'. In this reaction article, I challenge Gosselain's sweeping statements about ethnoarcaheology. In particular I argue against the notion that methodological weakness is unique to ethnoarchaeology, that the questions under study ignore the complexity of the social context, and that the search for cross-cultural regularities denies the historical dimension of technical practices. In conclusion, I suggest that rather than getting rid of ethnoarchaeology, it would be more helpful to meet the ambitious goals of ethnoarchaeology by improving and strengthening the methodology.
\end{abstract}

\section{Keywords}

ethnoarchaeology; analogies; social theory

It was with dismay that I recently read Gosselain's article 'To hell with ethnoarchaeology!' (Gosselain 2016). I had been aware of the French version of this article (Gosselain 2011), which was quoted in a Ph.D. thesis to support the idea that the search for cross-cultural regularities should be abandoned. My response here is, above all, driven by a sense of responsibility to students: I don't want them to be left with the confusion fuelled by this article, between approach and discipline, between good and bad studies, between ethnographic narratives and scientific constructs, between regularities and mechanisms, and between contextualized and non-contextualized reference data.

In his article, Gosselain starts by acknowledging that ethnoarchaeology 'developed as an effort to rationalize and systematize the use of analogies' (Gosselain 2016, 217). His first criticism relates to the contexts chosen for designing ethnoarchaeological projects. This context, he argues, is not only determined by the use of traditional materials (such as ceramics, metal, bone, hide and so on), but also affected by the image many have

*Valentine Roux, CNRS, France. Email: valentine.roux@cnrs.fr. 
of traditional societies. The latter would, according to Gosselain, lead ethnoarchaeologists to wrongfully select so-called 'primitive societies', to play down historical contingencies, to mask cultural specificities, and for some of them to back-pedal and opt only for direct historical studies. The main factors underlying the weakness of ethnoarchaeological studies, according to Gosselain, would be a methodological deficiency due to the lack of training of the archaeologists, the focus on narrow questions ignoring the complexity of the social context, and above all the denial of the historical dimension of technological practices. Gosselain winds up declaring that 'ethnoarchaeology is never as interesting as when it departs from the theoretical and ideological agenda upon which it was built; when, in other words, it mutates into a proper science of techniques and material culture, and engages with other disciplines' (Gosselain 2016, 225).

First, I want to point out that methodological deficiency is not specific to ethnoarchaeology. I could give numerous examples of significant methodological deficiencies in cultural anthropology, sociology, archaeology, and so on - in fact in the humanities in general (these methodological deficiencies have led us to distinguish between 'hard sciences' and 'soft sciences'). As an example I could underline how amazingly poor some cultural technological studies on apprenticeship are, while blatantly ignoring the methodological principles elaborated by experimental psychology. Imagine an article entitled 'To hell with cultural technology'!

My second point is to underline that methodology is to be assessed against the research questions asked. When the scope of a study is technical skills, obviously the methodology carried out is limited to this scope, and has no ambition to serve any other purpose, such as 'building social theory'. Gosselain states that such studies should be called 'experimental studies'. Why not, if it is, after all, a mere question of vocabulary? However, the aim of these studies, conducted at the level of the individual, is to explain regularities i.e. correlates linking artefacts or patterns of artefacts with attributes - which is the ultimate goal of ethnoarchaeology. Thus when studying skills in terms of learning duration, the aim is to explain in bio-behavioural terms (and therefore in cross-cultural terms) the regularities correlating types of object, techniques and learning duration. These regularities will then subsequently be used, for example, to found hypotheses on craft specialization (Roux 1989).

This leads me to the important distinction between two categories of ethnoarchaeological studies. In the domain of technology (my field of competence), we examine both static regularities (including diagnostic traits of object manufacturing process and function, skills, quantification of technical operations, social expression of technical traditions) and dynamic regularities (including dynamic phenomena of change) (Roux 2007).

The two categories of studies may have as an objective the analysis of the mechanisms underlying the regularities. In functional terms, a mechanism answers to the need to know how regularities are engendered (Manzo 2007, 45). Their study is necessarily conducted in collaboration with other disciplines. As an example of studies designed to explain the social expression of technical traditions, analysis of the learning process has engaged with experimental psychology in order to demonstrate that techniques are 
necessarily learned with a tutor and not individually (Bril 2002). Given that, as a general anthropological rule, tutors are always selected within one's social group, the learning process can then be conceived as the mechanism which explains the engendering of the regularity correlating technological and social boundaries. Other examples (among still others) are the cross-cultural quantification of elementary technical actions given both bio-behavioural and technical constraints (e.g. the number of pots a person can make per day using a given technique) in order to generate models of techno-systems (Roux and Matarasso 1999), the quantification of errors in the copying process depending on cultural habits in order to generate models of random morphometric evolution of ceramic shapes (Gandon, Roux and Coyle 2014), or the measures of geographical and/or social distances for explaining and generating the rhythm of diffusion of a technical trait as studied by sociologists (e.g. Hägerstrand 1965; Rogers 1962).

Gosselain considers that these studies focus on narrow questions and ignore the complexity of the social context. I argue, on the contrary, that these 'narrow issues' are extremely ambitious, since they aspire to explain how regularities are generated. Such an ambition supposes to change the level of analysis since 'the only units of analysis that can claim to have causal power and significance are situated at the level of individuals and their actions' (Manzo 2007, 45 n.; Cherkaoui 2005). In this respect, these studies do not ignore the complexity of the social context, but as in any solid scientific approach they focus on analytical units in a multi-level analytical framework aimed at relating the individual action (micro-level), the phenomenon under study (i.e. the regularities, meso-level), and the culturalhistorical specifics emerging from the latter (macro-level) (Mesoudi 2007). The methodology followed depends on the issue addressed and the questions asked (different types of field experiment, comparative observation situations, simulations).

Ethnoarchaeological studies may also highlight regularities without seeking to explain them, namely without calling upon generative mechanisms. The methodology consists in characterizing the context of observation, this context then defining the context of validity of the regularity. This context can be challenged by applying the regularity in as many different contexts as possible. The exercise is aimed at restricting progressively the context of validity and therefore making the regularity more robust. As an example, on the basis of investigations in Mali, decorative, technological and spatial criteria have been characterized for identifying prestigious recipients defined as objects 'taken from the economic and commercial sector to become part of the social, political and religious networks where they lose their use value and acquire sign value' (Gallay 2013,34). A way to test the cross-cultural value of these criteria is to examine them in other cultural contexts and assess, in particular, if a restricted distribution of decorated ceramics always indicates gifts for exceptional events such as marriages.

Contextualized regularities apply to dynamic phenomena as well, taking into account the historical dimension of technical practices, contrary to what Gosselain claims. However, the goal is to highlight anthropological regularities, which means not integrating the 'time' factor. As an example, Gelbert (2003) has examined the conditions for borrowing ceramic traits 
in Senegal. The proposed regularity states that in a context of large-scale production, the borrowing of fashioning techniques implying no motor difficulties (like the moulding technique) can occur through indirect contacts. Assessing the validity of this regularity requires applying it in different economic and cultural contexts. By reference to Gosselain's observation in Niger (Gosselain 2008), the borrowing of the moulding technique can indeed occur through indirect contacts, but also in low-production contexts. These two observations do not contradict each other, but supplement, through a comparative perspective, the conditions in which such a phenomenon occurs (Roux 2013). Recently, an ethnoarchaeological study in India has shown that, in context of large-scale production, broad diffusion of clay recipes and shapes was the result of indirect contacts (Roux 2015), thereby also arguing in favour of the regularity proposed by Gelbert, namely the possibility of borrowing traits through indirect contacts when they do not involve specific motor skills.

Finally, the studies invoking historical continuity highlight regularities that are not, by definition, cross-cultural. They are valid only in the cultural context where historical continuity has been observed. Usually these regularities are more specific and concern, for example, the relationship between ceramic style and ethnic group. In this respect, highlighting such relationships does not correspond to methodological back-pedalling. While the context of their application is more restricted, they can be studied side-byside with cross-cultural regularities.

In sum, ethnoarchaeology is, above all, an approach to highlighting anthropological regularities and unveiling their generative mechanisms, with the ultimate goal of applying these regularities to archaeological data. Methodology can borrow from experimental archaeology, engineering studies, experimental psychology, analytical sociology, economy, cultural anthropology, and so on, because understanding explanatory mechanisms is necessarily interdisciplinary. This has been superbly theorized by Gallay in his book published in 2011, but is curiously not discussed or even mentioned by Gosselain.

To conclude, even if ethnoarchaeological studies have not always lived up to expectations, often suffering from weak methodology, as underlined by Gosselain, the agenda of ethnoarchaeology remains as important today as ever. The search for cross-cultural regularities is essential both to interpret our archaeological data and to ground our theoretical models in empirical data. In this respect, rather than throwing the baby out with the bathwater, it would be more helpful to reify the necessity of solid methodology for meeting the ambitious goals of ethnoarchaeology.

\section{References}

Bril, B., 2002: Apprentissage et contexte, Intellectica 35, 251-68.

Cherkaoui, M., 2005: Invisible codes. Essays on generative mechanism, Oxford.

Gallay, A., 2011: Pour une ethnoarchéologie théorique, Paris.

Gallay, A., 2013: Biens de prestige et richesse en Afrique de l'Ouest. Un essai de définition, in C. Baroin and C. Michel (eds), Richesse et sociétés, Paris, 25-36. 
Gandon, E., V. Roux and T. Coyle, 2014: Copying errors of potters from three cultures. Predictable directions for a so-called random phenomenon, Journal of anthropological archaeology 33, 99-107.

Gelbert, A., 2003: Traditions céramiques et emprunts techniques dans la vallée du fleuve Sénégal, Paris.

Gosselain, O., 2008: Mother Bella was not a Bella. Inherited and transformed traditions in southwestern Niger, in M. Stark, B. Bower and L. Horne (eds), Cultural transmission and material culture. Breaking down boundaries, Tucson, 150-77.

Gosselain, O., 2011: A quoi bon l'ethnoarchéologie?, in P. Boissinot (ed.), L'archéologie comme discipline, Paris, 87-111.

Gosselain, O., 2016: To hell with ethnoarchaeology!, Archaeological dialogues 23(2), 215-28

Hägerstrand, T., 1965: A Monte Carlo approach to diffusion, European journal of sociology 6, 43-67.

Manzo, G., 2007: Variables, mechanisms, and simulations. Can the three methods be synthesized?, Revue française de sociologie 48, 35-71.

Mesoudi, A., 2007: Using the methods of social psychology to study cultural evolution, Journal of social evolutionary and cultural psychology 1, 35-58.

Rogers, E.M., 1962: Diffusion of innovations, New York.

Roux, V., 1989: The potter's wheel. Craft specialization and technical competence, New Delhi.

Roux, V., 2007: Ethnoarchaeology. A non historical science of reference necessary for interpreting the past, Journal of archaeological method and theory 14, $153-78$.

Roux, V., 2013: Ethnoarchaeology in France. Trends and perspectives, in A. Marciniak and N. Yalman (eds), Contesting ethnoarchaeologies, New York, $17-34$.

Roux, V., 2015: Standardization of ceramic assemblages. Transmission mechanisms and diffusion of morpho-functional traits across social boundaries, Journal of anthropological archaeology 40, 1-9.

Roux, V., and P. Matarasso, 1999: Crafts and the evolution of complex societies. New methodological perspectives for modeling the organization of production. An Harappan example, in M.A. Dobres and C.R. Hoffman (eds), The social dynamics of technology. Practice, politics and worldviews, Washington, 46-70. 